\title{
SVR Angiosarcomas can be Rejected by CD4 Costimulation Dependent and CD8 Costimulation Independent Pathways
}

\author{
Jack L. Arbiser, ${ }^{1}$ Adam Bingaman, ${ }^{2}$ Megan Durham, ${ }^{2}$ Shannon Cowan, ${ }^{2}$ Cynthia Cohen, ${ }^{3}$ \\ Elham Zarnegar, ${ }^{3}$ Vijay Varma, ${ }^{3}$ and Christian P. Larsen ${ }^{2}$ \\ Departments of Dermatology, ${ }^{1}$ Surgery, ${ }^{2}$ and Pathology, ${ }^{3}$ Emory University School of Medicine, \\ and Veterans Administration Medical Center, Atlanta, GA, USA
}

Accepted July 22, 2002

\begin{abstract}
Purpose: We wished to determine whether virallyinduced endothelial tumors are rejected by CD4 and CD8 lymphocytes, and whether there are differences in requirements for costimulation in the rejection of these tumors by lymphocyte subsets.

Experimental Design: We have developed a model of endothelial tumorigenesis through the sequential introduction of SV40 large T antigen and oncogenic $\mathrm{H}$-ras into endothelial cells. These cells (SVR cells) form highly aggressive angiosarcomas in immunocompromised mice, but do not grow in syngeneic C57BL/6 mice. Using both acute blockade with systemic administration of antibodies and mice genetically deficient in the costimulatory molecules CD28, CD40, and CD40L, we have delineated the requirements of costimulation required to reject this virally-induced endothelial tumor.
\end{abstract}

Results: Control of SVR angiosarcoma is mediated through $\mathrm{T}$ lymphocytes, and both CD4 and CD8 lymphocytes are capable of controlling SVR angiosarcoma growth in vivo. Mice genetically deficient in CD28, CD40, and CD40L were able to reject SVR tumors, but depletion of these mice of CD8, but not CD4 cells led to rapid tumor growth. This data suggests that CD4 mediated rejection has a greater dependence of costimulation than CD8 mediated rejection. Surprisingly, acute depletion of costimulatory molecules in immunocompetent C57BL/6 mice led to rapid tumor growth. Conclusions: Significant differences exist in the immune status of mice acutely depleted of costimulatory molecules versus genetically deficient mice. Our results suggest that acute depletion is more immunosuppressive than genetic depletion. Humans who undergo costimulatory blockade may require periodic surveillance for virally-induced tumors.

\section{Introduction}

The emergence of AIDS, as well as an increasing population of patients receiving immunosuppressive therapies for transplant regimens and inflammatory disorders, has led to an increased number of virallyinduced tumors. Patients infected with HIV have been demonstrated to have an increased frequency of virally induced tumors, such as Kaposi's sarcoma, HHV-8induced body cavity lymphoma (1-3), Epstein-Barr induced lymphoma, and anal squamous cell carcinoma $(4,5)$. These tumors are due in part to viral-specific oncogenes, such as human papillomavirus E6 and E7 (6), Epstein Barr LMP-1 (7), SV40 large T antigen in human mesothelioma $(8,9)$, HHV-8 specific G proteins, and IL-6 homologs (10-12). The role of the immune system in controlling the development of these tumors is demonstrated by the appearance of these tumors only when lymphocyte counts are severely depleted in AIDS patients, and regression of these tumors when immunity is partially restored through combination antiretroviral therapy (HAART) (13). Similarly, patients on immunosuppressive regimens including

Address correspondences and reprint requests to: J. L. Arbiser, Department of Dermatology, Emory University School of Medicine, WMB 5309, 1639 Pierce Drive Atlanta, GA 30322

Phone: 404-727-5063, fax: 404-727-0923, e-mail: jarbise@emory.edu cyclosporine and prednisone demonstrate a high incidence of virally induced tumors, of which regression can be induced upon reversal of immunosuppression. More recently, novel immunosuppressive molecules such as CTLA4-Ig and anti-CD40L/anti-CD40 based therapies are undergoing clinical trials as immunosuppressive agents for transplantation and severe inflammatory diseases such as psoriasis and graftversus-host disease $(14,15)$. The long-term consequences of these novel methods of immunosuppression are not known.

We have developed a model of endothelial tumorigenesis by sequential introduction of a temperature-sensitive SV40 large T antigen and oncogenic $\mathrm{H}$-ras into murine endothelial cells (16). In immunocompromised mice, these cells (SVR cells) form progressively growing tumors that lead to death of the host in 4 weeks, through invasive growth. However, in syngeneic C57BL/6 mice, only slight tumor growth is observed, followed by tumor regression. In this study we describe the role of lymphocyte subsets and costimulatory molecules in mediating rejection of this tumor. This model may be useful in rapidly establishing the efficacy of immunosuppressive regimens in preclinical studies, and may help predict whether novel forms of immunosuppression will lead to an increased incidence of virally induced tumors. 


\section{Materials and Methods \\ Mice}

Adult male 8-12 week old wild type (C57BL/6), C57BL/6 SCID, and C57BL/6 Nude mice were obtained from Jackson Laboratories (Bar Harbor, ME) and housed in specific pathogen free conditions. Similarly aged male CD40L $-/-$, CD40- - , and CD28-/- mice (all on C57BL/6 background) and RAGl -/- were obtained from Jackson Laboratories and bred as homozygotes under sterile conditions at Emory University.

Creation of Tumor Line and Administration of Tumor

SVR (ATCC 2280) cells were created by introducing temperature sensitive SV40 large T antigen (58-3 allele) and $\mathrm{H}$-ras oncogene into $\mathrm{C} 57 \mathrm{BL} / 6$ microvascular endothelial cells. $1 \times 10^{6} / 300 \mu \mathrm{L}$ SVR cells in cell culture media were injected subcutaneously into the lateral thoracic area using a total volume of $300 \mu \mathrm{L}$. Tumor volume was measured using the formula (width ${ }^{2} \times$ length) $\times 0.52$, where width represents the shortest dimension (16).

\section{T Cell Depletion}

GK 1.5 (anti-CD4) (100 $\mu \mathrm{g}$ ) and TIB105 (anti-CD8) $(100 \mu \mathrm{g})$ were given as intraperitoneal injections of $100 \mu \mathrm{g}$ on days $-3,-2,-1$ prior to SVR administration and weekly thereafter to deplete $\mathrm{CD} 4^{+}$and $\mathrm{CD} 8^{+}$ $T$ cells respectively. The antibodies were purified from ascites generated from the GK 1.5 and TIB 105 hybridoma cell lines, originally obtained from the American Type Culture Collection (Manassas, VA). Depletion of $\mathrm{T}$ cell subsets was confirmed by flow cytometry using anti-CD3, anti-CD4 (L3T4 clone) and anti-CD8 antibodies (Pharmingen, San Diego, CA and/or Caltag Laboratories, Burlingame, CA).

\section{Splenic Cell Preparation}

Spleen tissue was harvested from animals and made into a single cell suspension using a wire mesh and RPMI supplemented with 10\% FBS. Red cell lysis was performed using a proprietary lysis buffer solution from $\mathrm{R}+\mathrm{D}$ Systems (Minneapolis, MN). Cells were counted and $2 \times 10^{7}$ splenocytes were then injected intravenously via the penile vein concurrently with SVR inoculation.

Positive Selection of $\mathrm{CDB}^{+} \mathrm{T}$ Cells

C57BL/6 spleen and lymph nodes cells were made into single cell suspensions through a wire mesh, washed with RPMI supplemented with 10\% FBS and then placed over nylon wool columns. The enriched $T$ cells were then resuspended in $80 \mu$ l MACS buffer (PBS $+0.5 \%$ BSA +2 mM EDTA) per $2 \times 10^{7}$ cells. $20 \mu$ l MACS CD8 microbeads (Miltenyi Biotec, Bergisch Gladbach, Germany) per $10^{7}$ total cells were added and incubated at $4^{\circ} \mathrm{C}$ for $15 \mathrm{~min}$. Cells were then positively selected on the auto-MACS (Miltenyi Biotec). Pre- and post- samples were analyzed via flow cytometry (anti-CD4, anti-CD8a, anti-CD3, Pharmingen, San Diego, CA) to ensure purity.

\section{Immunomodulatory Agents}

$500 \mu \mathrm{g}$ of both hamster anti-mouse anti-CD40L mAb (MRl, Bioexpress, Lebanon, NJ) and CTLA4-Ig (provided by Diane Hollenbaugh, Bristol MyersSquibb) were administered intraperitoneally on days $0,2,4,6$ following SVR injection.

\section{Statistics}

Statistics were calculated with an unpaired Student $t$ test, and significance was assigned if the $p$ value was less than 0.05 .

\section{Results}

Transfer of Naive Syngeneic Lymphocytes from C57BL/6 Mice to SCID Mice Bearing Tumor Leads to Rejection of Tumor

SVR cells do not produce progressive tumors in syngeneic C57BL/6 mice, but form rapidly growing tumors in nude and SCID mice. In order to determine whether this difference was immune mediated, we transferred splenocytes from naïve adult C57BL/6 mice to C57BL/ 6/SCID mice bearing SVR tumors. Mice receiving splenocytes on the same day or at day 7 after inoculation of $1 \times 10^{6}$ SVR cells were able to control and eliminate tumors, while mice receiving splenocytes on day 14 or unreconstituted mice showed rapid tumor growth, ultimately necessitating sacrifice. Tumor size was assessed at one month after SVR inoculation, at which point animals were sacrificed due to large tumors.

\section{$\mathrm{CD}^{+}$and $\mathrm{CD}^{+} \mathrm{T}$ lymphocytes are Capable}

of Rejecting the Tumor

Syngeneic mice were depleted of $\mathrm{CD}^{+}$and $\mathrm{CD}^{+}$ $\mathrm{T}$ cells by intraperitoneal injection of GK 1.5 (antiCD4) and TIB 105 (anti-CD8) antibodies, either alone, or in combination, and were inoculated with $5 \times 10^{5}$ SVR cells subcutaneously. As a positive control, SVR cells were injected into C57BL6/SCID mice, and as a negative control, SVR cells were injected into syngeneic C57BL/6 mice. Depletion of both CD4 and CD8 subsets was confirmed by flow cytometry (Fig. 1).
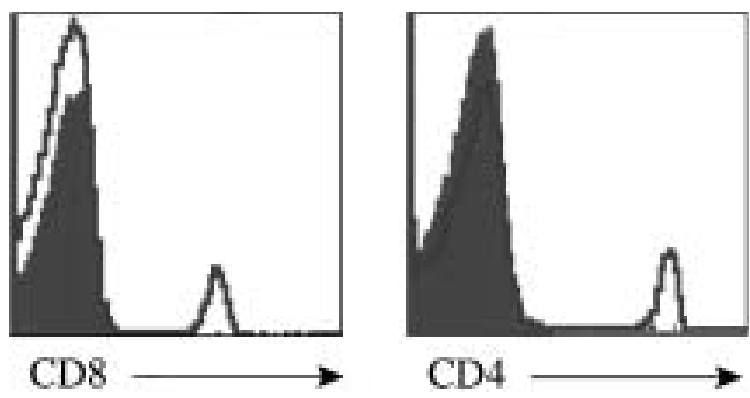

Fig. 1. In vivo depletion of $\mathrm{CD4}^{+}$and $\mathrm{CD8}^{+} \mathrm{T}$ cells. Animals were treated with $100 \mu \mathrm{g}$ GK 1.5 (anti-CD4) and/or $100 \mu \mathrm{g}$ TIB 105 (anti-CD8) i.p. on days $-3,-2,-1$, and weekly thereafter (relative to SVR injection). Shown above are flow cytometric histogram analyses of peripheral blood confirming adequate in vivo depletion. Solid histograms represent animals depleted with the respective mAb. The overlaying histograms represent undepleted control animals. The $\mathrm{x}$ axis represents log fluorescence intensity and the y axis represents cell number. 


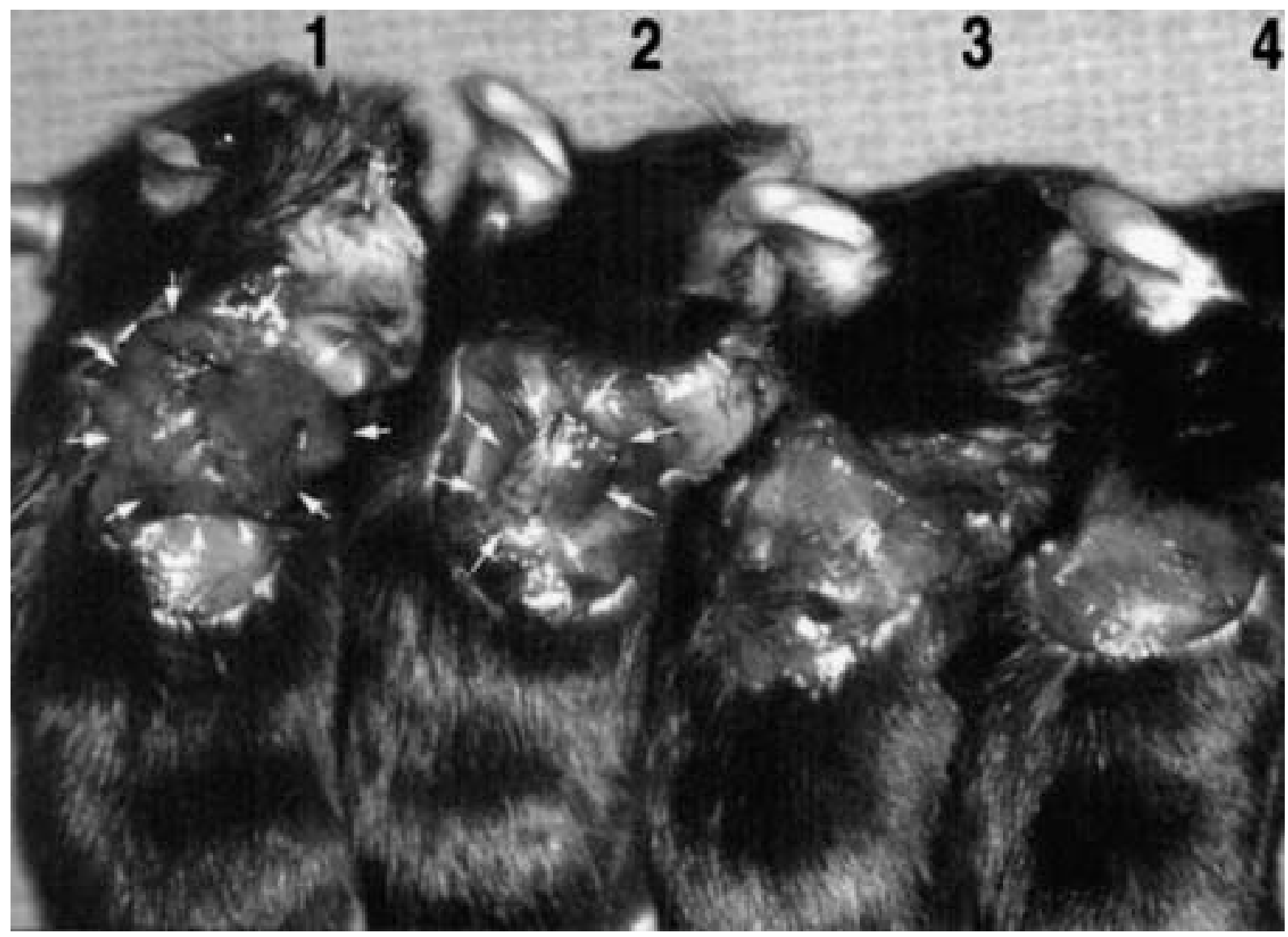

Fig. 2A. Gross appearance of mice at day 12 of immunosuppression. 5 mice were treated in each of the antibody groups, and 5 mice received SVR cells in the absence of antibody. Arrows are surrounding the tumor in the mouse on the left (\#1), which is in a mouse depleted of both CD4 and CD8 cells, and the second mouse from the left (\#2), which was depleted of CD8 cells. No tumor was visible in mice depleted of CD4 cells (second from right, \#3), or undepleted mice (mouse on right, \#4).

Mice depleted of both CD4 and CD8 subsets developed rapidly growing tumors necessitating sacrifice at two weeks after injection. Tumors were initially observed in CD8 depleted mice at two weeks, followed by regression, while little tumor was visible in CD4 depleted mice, or immunocompetent mice (Fig. 2A). Tumors were measured at two and three weeks (Fig. 2B), and one mouse from each group was sacrificed at two weeks for histologic evaluation. Extensive lymphocytic infiltrate was observed in an SVR tumor

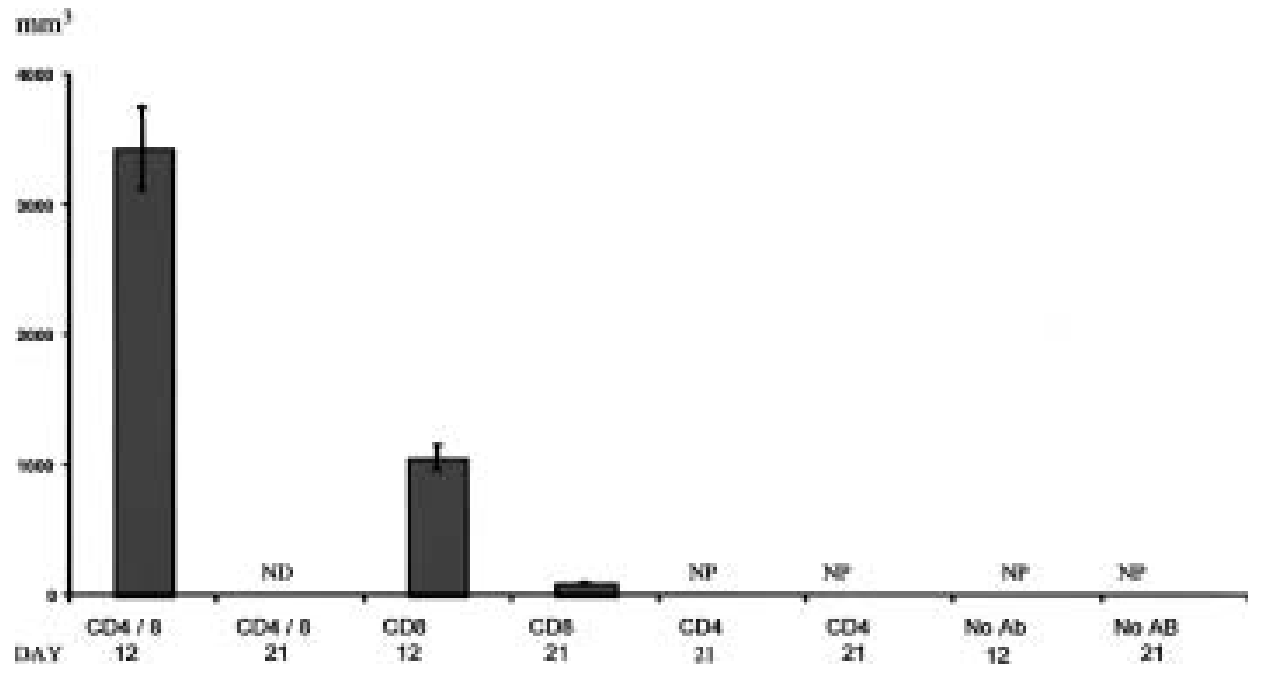

Fig. 2B. Tumor volume of mice depleted of $\mathrm{CD} 4$ and $\mathrm{CD8}$ antibodies. Mice depleted of both antibodies were sacrificed on day 12 due to progressive tumor growth. Regression was observed in mice depleted of CD8 lymphocytes between days 12 and 20 after inoculation, despite ongoing immunosuppression. No palpable tumors were observed in mice depleted of CD4 lymphocytes or mice receiving no antibody. ND stands for not determined, as mice were sacrificed at day 12 because of large tumor volume. NP stands for tumor not palpable. 

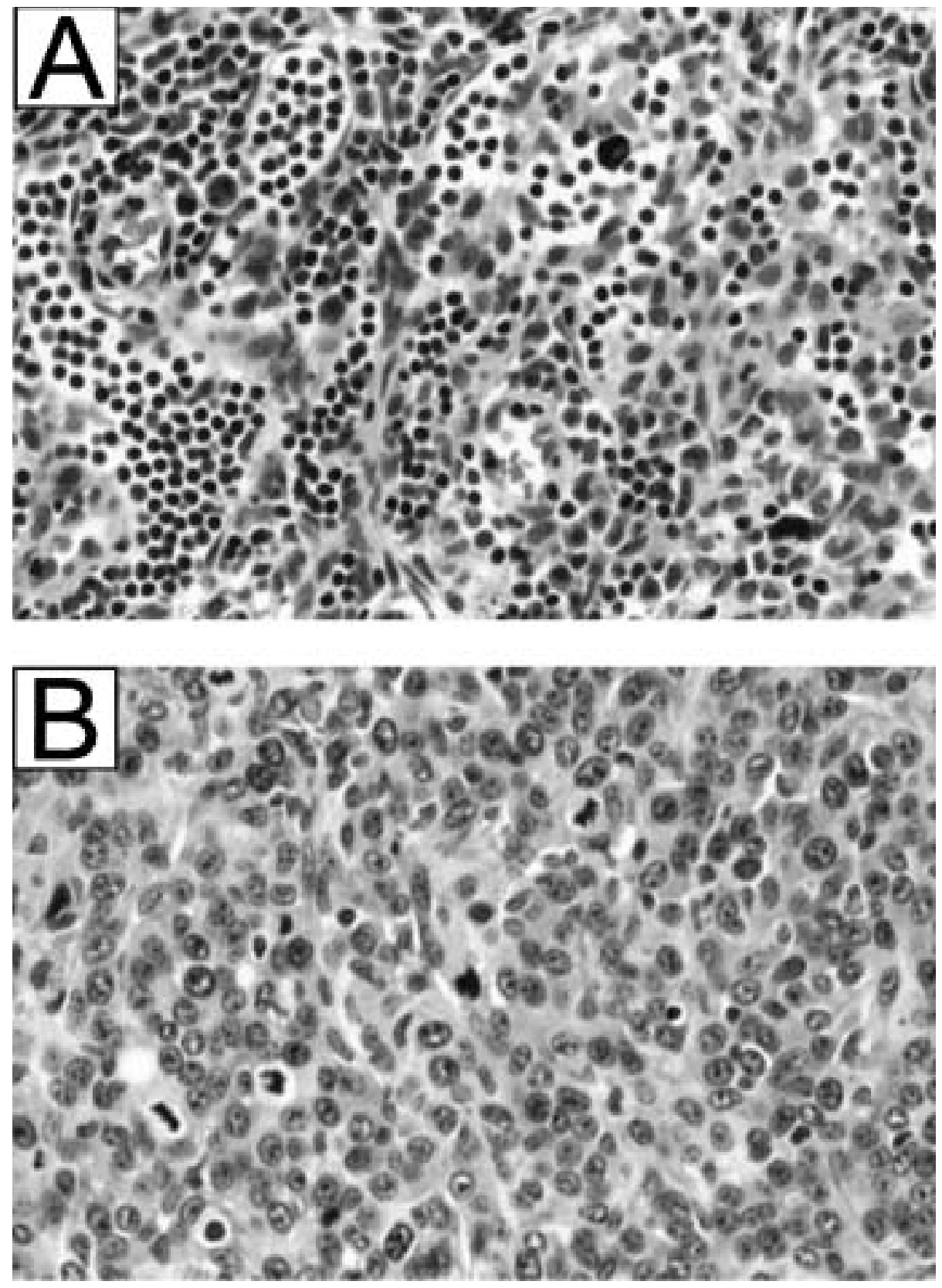

Fig. 2C. Hematoxylin and eosin staining of SVR cells undergoing rejection in immunocompetent C57BL6 mice after at day 12 after inoculation, showing intense lymphocytic infiltration $(100 \times)$. (Top, A). Histology of a representative SVR tumor at day 12 after inoculation into C57BL6 mouse depleted of both CD4 and CD8 lymphocytes (100×) (Bottom, B). injected into an immunocompetent C57BL6 mouse, while the tumor developing in a CD4/CD8 doubly depleted mouse showed little infiltrate (Fig. 2C).

\section{Transfer of Nä̈ve CD8 Cells is Sufficient to Cause Rejection of SVR Cells}

In order to determine whether infusion of naïve CD8 cells alone are capable of rejecting SVR tumors, SCID mice were injected with SVR tumor cells, and were infused with $\mathrm{CD}^{+}$and $\mathrm{CD}^{+}$lymphocytes in combination, CD8+ lymphocytes alone, or no lymphocytes. $2 \times 10^{7}$ lymphocytes were infused into each mouse. Five mice were treated in each group. Lymphocyte enrichment was confirmed by flow cytometry (Fig. 3A). Both combined CD4/CD8 lymphocyte infusion and infusion of $\mathrm{CD}^{+}$lymphocytes alone were capable of eradicating tumor. Surprisingly, $\mathrm{CD}^{+}$infusion alone lead to slightly more rapid eradication of tumor than combined lymphocyte infusion, but tumors were eradicated in both groups. Mice receiving no lymphocytes succumbed to tumor growth (Fig. 3B).

\section{CD4 Mediated Rejection of Tumor is Dependent on CD28, CD40, and CD40L}

In order to determine the effect of costimulatory molecules on the ability to control SVR cells in C57BL/6 mice, $5 \times 10^{5}$ SVR cells were injected 


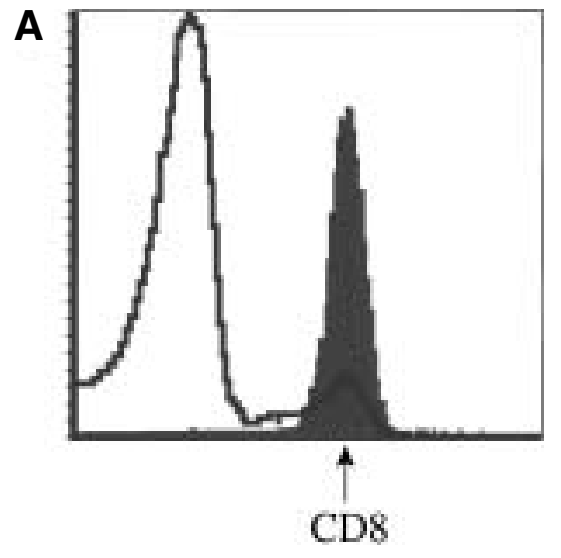

Fig. 3A. Positive selection with anti-CD8 microbeads allowed for purification of $\mathrm{CD8}^{+} \mathrm{T}$ cells from C57BL6 spleen and lymph nodes. The histogram shows the enrichment of $\mathrm{CD}^{+}$cells (solid histogram, CD8 ${ }^{+}$cells $=99.2 \%$ following positive selection as compared to an unenriched sample (open histogram, $\mathrm{CD}^{+}$cells $=10.95 \%$ ). The $\mathrm{x}$ axis represents $\log$ fluorescence intensity and the y axis represents cell number.

into CD28-/-, CD40-/- and CD40L-/- mice. All of these mice were able to reject SVR cells. These knockout mice were then depleted of $\mathrm{CD} 4{ }^{+}$ and $\mathrm{CD}^{+}$cells by intraperitoneal injection of antiCD4 or anti-CD8 antibodies. Mice deficient in CD 28, CD40, and CD40L and deficient in CD4+ $\mathrm{T}$ cells were able to control tumor growth, while depletion of $\mathrm{CD}^{+} \mathrm{T}$ cells in these mice allowed progressive tumor growth (Fig. 4A-B). These data suggest that $\mathrm{CD}^{+} \mathrm{T}$ cell control of tumors is dependent on intact functioning of the costimulatory pathways CD28, CD40-CD40L, while CD8 mediated rejection of SVR cells may be less dependent on costimulation. Surprisingly, CD28 knockout mice depleted of CD8 cells grew significantly larger tumors than SCID mice $(p<0.05)$.

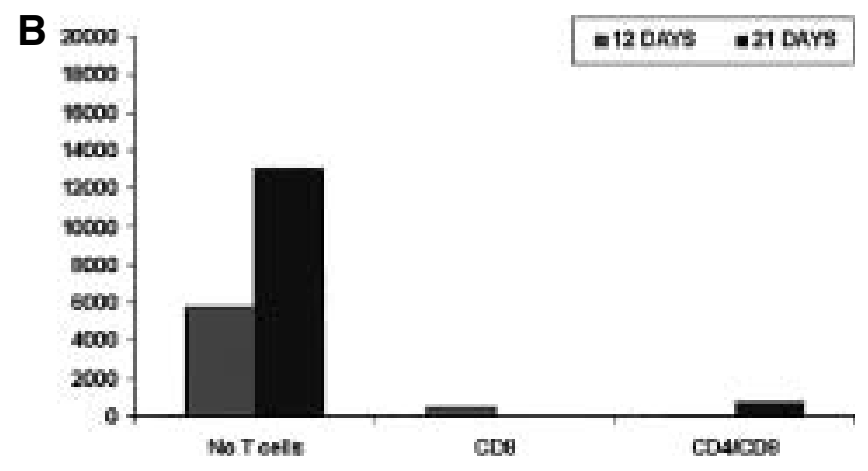

Fig. 3B. Effect of infusion of $\mathrm{CD8}^{+}$lymphocytes alone, or combined CD4/CD8 lymphocyte infusion on control of SVR tumor growth in vivo. The y axis represents tumor volume on day 12 (green) or day 21 (blue). Mice receiving no lymphocytes died of tumor, while mice receiving either CD8 ${ }^{+}$ lymphocytes alone or in combination with $\mathrm{CD}^{+}$lymphocytes were able to reject tumors.
Effect of Single Blockade of CTLA4-Ig and Anti-CD4OL in Syngeneic Mice

In order to determine whether either CTLA4-Ig or anti-CD40L was sufficient alone to allow SVR tumor growth in syngeneic C57BL6 mice, mice were injected with $5 \times 10^{5}$ SVR cells, and immunosuppressed with each agent individually. Mice were injected with immunosuppressive agent on the same day as injection with SVR (day 0 ), and on days 2,4 , and 6 after injection with SVR cells. All animals treated with either CTLA4-Ig or anti-CD40L experienced large tumor growth and eventually succumbed to their disease. Combined therapy with CTLA4-Ig and anti-CD40L also lead to large tumor growth, but was not significantly different from individual therapy with CTLA4-Ig or anti-CD40L (data not shown).

\section{Discussion}

$\mathrm{T}$ lymphocytes are required for the control of virally induced tumors of both animals and humans. This is clinically evident in the increased incidence of virally induced cancers, such as lymphomas due to EBV, Kaposi's sarcoma due to HHV8, and cervical/anal carcinomas due to HPV $(17,18)$. The functional requirements for control of virally induced tumors in humans is difficult to study, as reconstitution of the human immune system in the clinical setting of virally induced tumors is often difficult, especially in the setting of acquired immune deficiency syndrome (AIDS). Regression of virally induced tumors and lymphoproliferative disorders has been seen in transplant patients in which iatrogenic immunosuppression has been reversed by discontinuation of drugs $(19,20)$. Regression of Kaposi's sarcoma has been occasionally observed in AIDS patients receiving highly effective antiretroviral therapy (HAART) (21-23). However, knowledge of the precise subsets of cells responsible for rejection of virally induced tumors has not been well studied, partially due to the difficulties in sampling regressing tumors in humans. We have developed a model of a virally induced tumor through the sequential introduction of a temperature sensitive large $\mathrm{T}$ antigen and oncogenic $\mathrm{H}$-ras into $\mathrm{C} 57 \mathrm{BL} / 6$ microvascular endothelial cells. The resulting angiosarcomas do not grow in adult syngeneic C57BL6 mice, but grow well in allogeneic nude or SCID mice (16). We used this model to study the immune requirements for growth of these tumors. Infusion of naïve $\mathrm{T}$ lymphocytes into mice bearing tumor led to rejection of tumor growth, and lymphocytes were observed in the tumor, indicating that rejection of the tumor was immune mediated. Tumors failed to grow continuously in C57BL6 mice depleted of either $\mathrm{CD}^{+}{ }^{+}$or $\mathrm{CD}^{+}{ }^{+} \mathrm{T}$ cell subsets, or in mice homozygous for CD28, CD40, or CD40L. However, vigorous tumor growth was observed in mice homozygous for CD28, CD40, and CD40L mice 


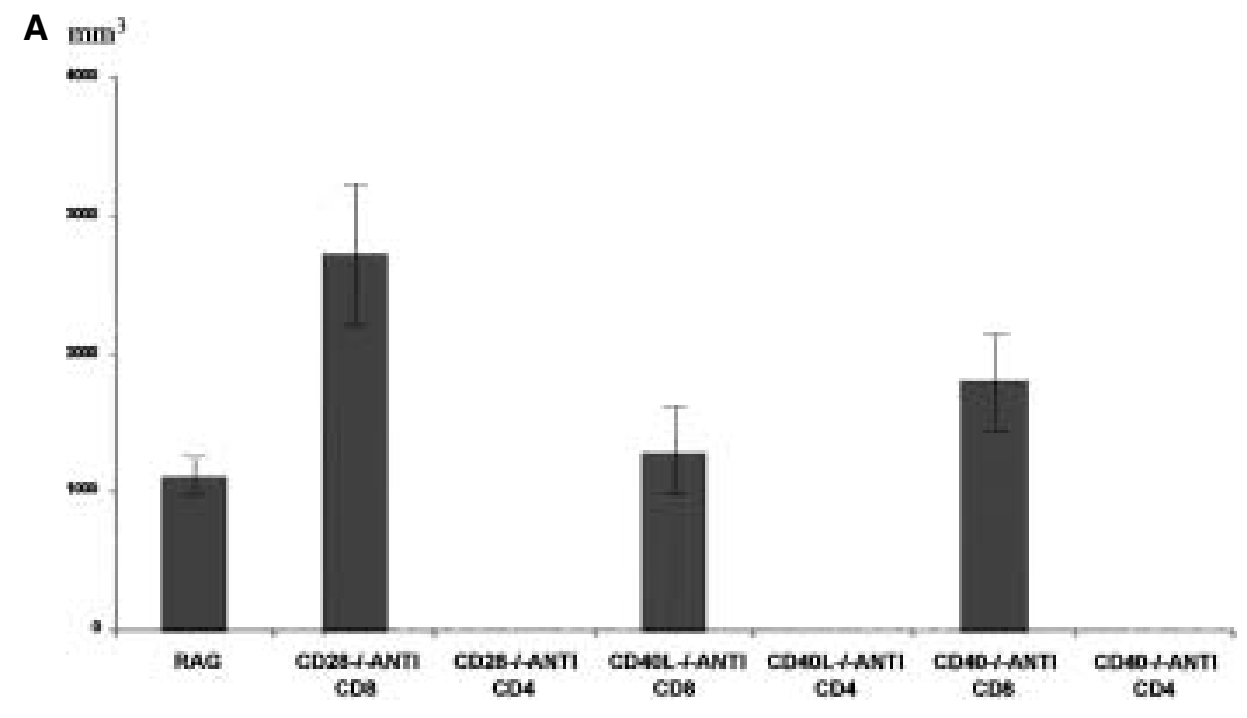

Fig. 4A. Effect of $\mathrm{CD4}^{+}$and $\mathrm{CD8}^{+}$ depletion on SVR tumor growth in CD28 $-l-$, CD40L $-l-$, and CD40-I- mice. The y axis represents tumor size. Tumors in CD8 depleted CD28-/- mice are significantly larger than positive control RAGl - /- knockout mice. depleted of $\mathrm{CD}^{+}$but not $\mathrm{CD} 4^{+}$cells. This indicates that $\mathrm{CD}^{+}$and $\mathrm{CD}^{+}$cells can reject SVR tumors independently, but $\mathrm{CD}^{+}$mediated rejection may have a greater requirement for costimulatory pathways.
Rejection of SV40-induced tumors has been studied in transgenic models in which large $\mathrm{T}$ antigen is targeted to an organ using a specific promoter (24-26). In these cases, tolerance may develop to large $\mathrm{T}$ antigen because the animal is exposed to

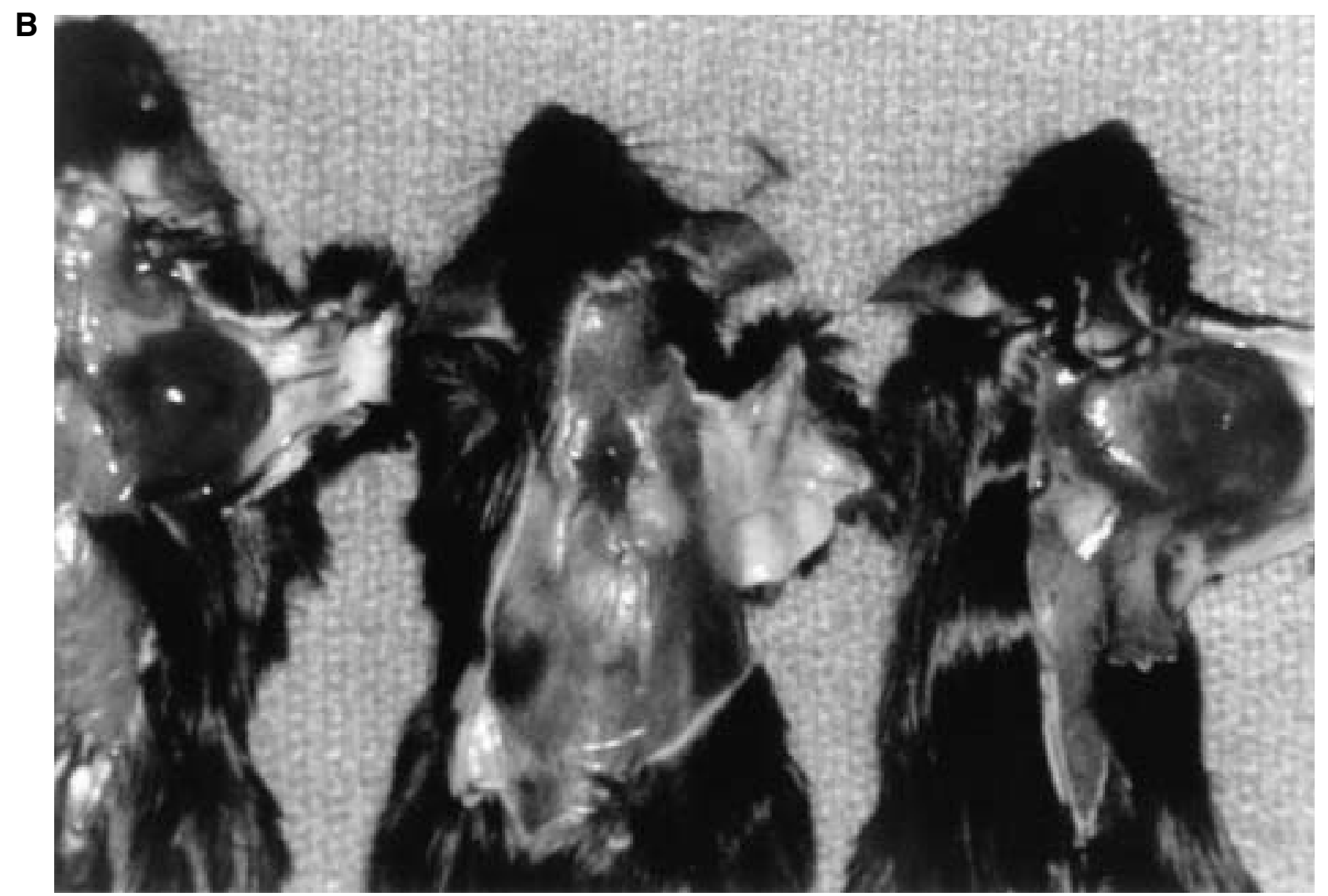

Fig. 4B. Representative appearance of tumors in mice. Mouse on left represents C57BL6/SCID containing SVR tumor, mouse in middle is a representative CD28-/- mouse depleted of CD4 ${ }^{+}$cells followed by SVR injection, and mouse on right is a representative CD28-I- mouse depleted of $\mathrm{CD}^{+}$cells followed by SVR injection. 
this protein at an early age. The mode of presentation of antigen may also play a role, and differences in cytotoxic T cell responses to SV40 large T antigen have been observed depending on whether the antigen is introduced in the form of virus, recombinant DNA, or tumor cell expressing $\mathrm{T}$ antigen (27-30). We believe our model has relevance to adult tumors, as many tumor virus infections may occur during adulthood, including EBV, HPV, and HHV8 infections. Viral induced cancers have also been recently demonstrated to have mutations in ras family oncogenes as a second hit, similar to our model $(31,32)$.

Our findings show significant differences with other established models of transplant rejection. $\mathrm{CD}^{+}{ }^{+}$blockade is sufficient to cause long-term cardiac allograft acceptance in mice $(33,34)$. In the case of acceptance of allogeneic skin, combined blockade of the CD40 and CD28 pathways is insufficient to cause long-term acceptance, and the rejection of skin may be mediated by a novel class of activated $\mathrm{T}$ cells which express an NK like marker, asialo-GMI (35). Acceptance of our tumor shows an intermediate phenotype, in that depletion of CD4 is insufficient to promote in vivo tumor growth, but blockade of CD28 and CD40 with CLTA4-Ig and MRI antibodies allows vigorous tumor growth.

Immune responses to murine tumors have been demonstrated in several nonendothelial models (36-38). In several of these studies, CD8 mediated rejection of tumor was costimulation dependent. In our study, we found that CD8 lymphocytes were able to eliminate tumor in the absence of CD28, CD40, and CD40L, but these costimulatory molecules were required for CD4 mediated rejection. Thus, the requirements for rejection via costimulatory molecules differ between tumor types.

Interestingly, tumor growth was more vigorous in the CD28 -/- mice depleted of CD8 lymphocytes than in the more immunocompromised RAGl -/knockout mice. This implies that under certain conditions, partial immunosuppression may be increase or decrease susceptibility to tumor growth compared with severe immunosuppression. This phenomenon has been observed in both mice and humans. Vaccination of tumor prone mice with tumor antigens has been shown to enhance tumor growth, and this tumor growth is CD4 mediated (39). Mice partially immunosuppressed by expressing a transgene for CTLA4-Ig showed decreased ultraviolet-induced tumor formation compared with wild type mice (40). Humans with concurrent chronic lymphocytic leukemia and squamous cell carcinoma have skin cancers highly infiltrated with lymphocytes and an aggressive course $(41,42)$. These data suggest that certain lymphocyte populations may contribute to tumor growth.

We compared our results of growth of SVR tumor cells in mice deficient in the costimulatory molecules CD28, CD40, and CD40L with syngeneic immuno- competent C57BL6 mice treated with CTLA4-Ig and anti-CD40L antibodies alone. Surprisingly, tumor growth was vigorous in immunocompetent mice treated with either CTLA4Ig or MRI alone, compared with the corresponding knockout mice. Thus, in our system, antibody mediated immunosuppression is more effective than genetic knockout of costimulatory molecules. We are uncertain of the reasons for this difference, but compensation may exist in the knockout mice that are not present in the antibody treated mice. Current knowledge of the immune system suggests several possibilities for the differences we observed between acute costimulation blockade versus genetic costimulation blockade. These possibilities include a strong inhibitory effect on gamma delta T lymphocytes due to acute costimulation blockade, versus preservation of gamma delta $\mathrm{T}$ cell function in genetic knockout mice $(43,44)$. Gamma delta $\mathrm{T}$ cells have been demonstrated to play a crucial role in the defense against cutaneous squamous cell carcinoma and may be important in defense against other malignancies (45). Other possibilities include upregulation of alternative costimulatory molecules, such as ICOS, in genetically deficient mice $(46,47)$. These possibilities are currently under investigation in our laboratory. Finally, our data suggests that patients receiving costimulatory blockade may be at increased risk for virally induced malignancy.

\section{Acknowledgements}

JLA was supported in part by the American Skin Association and grants AR02030, AR44947, and ROIAR47901 from the National Institutes of Health. AB, MD, SC, and CL were supported in part by grants DK50762, DK/AI 40519, AI44644, and P30AR42687 (Emory Skin Disease Research Core Center Grant) from the National Institutes of Health, EEC Award 9731643 from the National Science Foundation, and the Carlos and Marguerite Mason Trust.

\section{References}

1. Blauvelt A. (1999) The role of human herpesvirus 8 in the pathogenesis of Kaposi's sarcoma. Adv. Dermatol. 14: 167206.

2. Offermann MK. (1999) Consideration of host-viral interactions in the pathogenesis of Kaposi's sarcoma. J. Acquir. Immune Defic. Syndr. 21 Suppl. 1: S58-S65.

3. Chang Y, Cesarman E, Pessin MS, et al. (1994) Identification of herpesvirus-like DNA sequences in AIDS-associated Kaposi's sarcoma. Science 266(5192): 1865-1869.

4. Henle W, Diehl V, Kohn G, et al. (1967) Herpes-type virus and chromosome marker in normal leukocytes after growth with irradiated Burkitt cells. Science 157(792): 10641065

5. zur HH, de Villiers EM, Gissmann L. (1981) Papillomavirus infections and human genital cancer. Gynecol. Oncol. $12(2$ Pt 2): S124-S128.

6. Howley PM. (1983) The molecular biology of papillomavirus transformation. Warner-Lambert Parke-Davis Award Lecture. Am. J. Pathol. 113(3): 414-421. 
7. Kaye KM, Izumi KM, Kieff E. (1993) Epstein-Barr virus latent membrane protein 1 is essential for B- lymphocyte growth transformation. Proc. Natl. Acad. Sci. USA 90(19): 9150-9154.

8. Rizzo P, Carbone M, Fisher SG, et al. (1999) Simian virus 40 is present in most United States human mesotheliomas, but it is rarely present in non-Hodgkin's lymphoma. Chest 116 (6 Suppl): 470S-473S.

9. Carbone M, Pass HI, Rizzo P, et al. (1994) Simian virus 40-like DNA sequences in human pleural mesothelioma. Oncogene 9(6): 1781-1790.

10. Bais C, Santomasso B, Coso O, et al. (1998) G-proteincoupled receptor of Kaposi's sarcoma-associated herpesvirus is a viral oncogene and angiogenesis activator. Nature 391(6662): $86-89$.

11. Aoki Y, Jones KD, Tosato G. (2000) Kaposi's sarcoma-associated herpesvirus-encoded interleukin-6. J. Hematother Stem Cell Res. 9(2): 137-145.

12. Moore PS, Boshoff C, Weiss RA, Chang Y. (1996) Molecular mimicry of human cytokine and cytokine response pathway genes by KSHV. Science 274(5293): 1739-1744.

13. Lebbe C, Blum L, Pellet C, et al. (1998) Clinical and biological impact of antiretroviral therapy with protease inhibitors on HIV-related Kaposi's sarcoma. AIDS 12(7): F45F49.

14. Abrams JR, Lebwohl MG, Guzzo CA, et al. (1999) CTLA4Igmediated blockade of T-cell costimulation in patients with psoriasis vulgaris. J. Clin. Invest. 103(9): 1243-1252.

15. Guinan EC, Boussiotis VA, Neuberg D, et al. (1999) Transplantation of anergic histoincompatible bone marrow allografts. N. Engl. J. Med. 340(22): 1704-1714.

16. Arbiser JL, Moses MA, Fernandez CA, et al. (1997) Oncogenic $\mathrm{H}$-ras stimulates tumor angiogenesis by two distinct pathways. Proc. Natl. Acad. Sci. USA 94(3): 861-866.

17. Otley CC, Pittelkow MR. (2000) Skin cancer in liver transplant recipients. Liver Transpl. 6(3): 253-262.

18. Shmueli D, Shapira Z, Yussim A, et al. (1989) The incidence of Kaposi sarcoma in renal transplant patients and its relation to immunosuppression. Transplant Proc. 21(1 Pt 3): 32093210.

19. Kalra PA, Wood GN, O'Donoghue DJ, et al. (1994) Complete regression of recurrent diffuse malignant lymphoma after withdrawal of cyclosporin $\mathrm{A}$ in a renal transplant recipient. Nephrol Dial Transplant 9(8): 1197-1200.

20. Fric M, Hartmann A, Klehr HU, et al. (1990) (Regression of cerebral post-transplantation lymphoma under cyclosporin A reduction). Klin Wochenschr 68(23): 1189-1194.

21. Vaccher E, di Gennaro G, Nasti G, et al. (1999) HAART is effective as anti-Kaposi's sarcoma therapy only after remission has been induced by chemotherapy. J. Acquir. Immune Defic. Syndr. 22(4): 407-408.

22. Bower M, Fox P, Fife K, et al. (1999) Highly active antiretroviral therapy (HAART) prolongs time to treatment failure in Kaposi's sarcoma. AIDS 13(15): 2105-2111.

23. Parra R, Leal M, Delgado J, et al. (1998) Regression of invasive AIDS-related Kaposi's sarcoma following antiretroviral therapy. Clin. Infect. Dis. 26(1): 218-219.

24. Schell TD, Mylin LM, Georgoff I, et al. (1999) Cytotoxic T-lymphocyte epitope immunodominance in the control of choroid plexus tumors in simian virus 40 large $\mathrm{T}$ antigen transgenic mice. J. Virol. 73(7): 5981-5993.

25. Jolicoeur C, Hanahan D, Smith KM. (1994) T-cell tolerance toward a transgenic beta-cell antigen and transcription of endogenous pancreatic genes in thymus. Proc. Natl. Acad. Sci. USA 91(14): 6707-6711.

26. Ohashi PS, Oehen S, Buerki K, et al. (1991) Ablation of "tolerance" and induction of diabetes by virus infection in viral antigen transgenic mice. Cell 65(2): 305-317.

27. Gooding LR. (1977) Specificities of killing by cytotoxic lymphocytes generated in vivo and in vitro to syngeneic SV40 transformed cells. J. Immunol. 118(3): 920-927.
28. Bright RK, Beames B, Shearer MH, Kennedy RC. (1996) Protection against a lethal challenge with SV40-transformed cells by the direct injection of DNA-encoding SV40 large tumor antigen. Cancer Res. 56(5): 1126-1130.

29. Jennings SR, Fresa KL, Lippe PA, et al. (1988) Frequency analysis of simian virus 40 -specific cytotoxic $\mathrm{T}$ lymphocyte precursors in the high responder $\mathrm{C} 57 \mathrm{BL} / 6$ mouse strain. J. Gen. Virol. 69 (Pt 10): 2493-2503.

30. Mylin LM, Bonneau RH, Lippolis JD, Tevethia SS. (1995) Hierarchy among multiple $\mathrm{H}-2 \mathrm{~b}$-restricted cytotoxic T-lymphocyte epitopes within simian virus $40 \mathrm{~T}$ antigen. J. Virol. 69(11): 6665-6677.

31. Radkov SA, Kellam P, Boshoff C. (2000) The latent nuclear antigen of Kaposi sarcoma-associated herpesvirus targets the retinoblastoma-E2F pathway and with the oncogene Hras transforms primary rat cells. Nat. Med. 6(10): 11211127.

32. Nicolaides A, Huang YQ, Li JJ, et al. (1994) Gene amplification and multiple mutations of the $\mathrm{K}$-ras oncogene in Kaposi's sarcoma. Anticancer Res. 14(3A): 921-926.

33. Larsen CP, Elwood ET, Alexander DZ, et al. (1996) Long-term acceptance of skin and cardiac allografts after blocking CD40 and CD28 pathways. Nature 381(6581): 434-438.

34. Pearson TC, Madsen JC, Larsen CP, et al. (1992) Induction of transplantation tolerance in adults using donor antigen and anti-CD4 monoclonal antibody. Transplantation 54(3): $475-483$.

35. Trambley J, Bingaman AW, Lin A, Elwood ET, et al. (1999) Asialo GMl(+) CD8(+) T cells play a critical role in costimulation blockade-resistant allograft rejection. J. Clin. Invest. 104(12): 1715-1722.

36. Chen L, Ashe S, Brady WA, et al. (1992) Costimulation of antitumor immunity by the B7 counterreceptor for the T lymphocyte molecules CD28 and CTLA-4. Cell 71(7): 10931102.

37. Chen L, Linsley PS, Hellstrom KE. (1993) Costimulation of T cells for tumor immunity. Immunol. Today 14(10): 483-486.

38. Zhan Y, Corbett AJ, Brady JL, et al. (2000) CD4 helpindependent induction of cytotoxic CD8 cells to allogeneic P815 tumor cells is absolutely dependent on costimulation. J. Immunol. 165(7): 3612-3619.

39. Siegel CT, Schreiber K, Meredith SC, et al. (2000) Enhanced growth of primary tumors in cancer-prone mice after immunization against the mutant region of an inherited oncoprotein. J. Exp. Med. 191(11): 1945-1956.

40. Beissert S, Bluestone JA, Mindt I, et al. (1999) Reduced ultraviolet-induced carcinogenesis in mice with a functional disruption in B7-mediated costimulation. J. Immunol. 163(12): 6725-6731.

41. Levi F, Randimbison L, Te VC, La Vecchia C. (1996) NonHodgkin's lymphomas, chronic lymphocytic leukaemias and skin cancers. Br. J. Cancer 74(11): 1847-1850.

42. Bridges N, Steinberg JJ. (1986) Aggressive squamous cell carcinoma of the skin after chronic lymphocytic leukemia. J. Surg. Oncol. 33(1): 27-30.

43. Sperling AI, Linsley PS, Barrett TA, Bluestone JA. (1993) CD28-mediated costimulation is necessary for the activation of $\mathrm{T}$ cell receptor-gamma delta $+\mathrm{T}$ lymphocytes. J Immunol. 151(11): 6043-6050.

44. Penninger JM, Timms E, Shahinian A, et al. (1995) Alloreactive gamma delta thymocytes utilize distinct costimulatory signals from peripheral T cells. J. Immunol. 155(8): 3847-3855.

45. Girardi M, Oppenheim DE, Steele CR, et al. (2001) Regulation of cutaneous malignancy by gammadelta $\mathrm{T}$ cells. Science 294(5542): 605-609.

46. Hutloff A, Dittrich AM, Beier KC, et al. (1999) ICOS is an inducible T-cell co-stimulator structurally and functionally related to CD28. Nature 397(6716): 263-266.

47. Riley JL, Blair PJ, Musser JT, et al. (2001) ICOS costimulation requires IL-2 and can be prevented by CTLA-4 engagement. J. Immunol. 166(8): 4943-4948. 